\title{
CHASSÉRIAU: ENTRE TENSÕES, SUA ARTE SINGULAR
}

\author{
Martinho Alves da Costa Junior \\ CISC/PUC-SP
}

Esta comunicação tem como objetivo pôr em discussão a obra de Théodore Chassériau. A produção acerca a obra deste pintor, no cenário nacional, ainda é escassa. Porém, vem continuamente ganhando espaço e importância em diversas publicações, principalmente na França e nos Estados Unidos. Quando começa sua participação nos salões oficiais de Paris, importantes críticos expressaram suas opiniões, dentre os quais Théophile Gautier. Foi em 1839 que Gautier pela primeira vez cita Chassériau, este que seria o grande crítico e amigo do pintor, fiel e confiante na obra de Chassériau: "Predizemos para Monsieur Chassériau um futuro dos mais brilhantes e, sem ter a pretensão de ser profeta, nós raramente nos enganamos em nossas predições". Seus dois primeiros biógrafos, ainda hoje nos dão pistas valiosas quanto a sua vida e obra. Valbert Chevillard publica em 1893 a primeira monografia inteiramente destinada ao pintor: Théodore Chassériau: Un Peintre Romantique. Recheado de citações e reproduções de diversas cartas do pintor, o autor, de modo entusiástico, faz seu relato. Léonce Bénédite escreve Théodore Chassériau. Sa vie et son cuvre. Trata-se de um manuscrito inédito de 1911 que somente foi publicado em 1931 por André Dezarrois em dois volumes. Em 1974 aparece o Théodore Chassériau. 1819-1856. Catalogue Raisonné des peinture et estampes. de Marc Sandoz. Uma obra muito importante que de certa forma abre perspectivas para uma leitura mais ampla sobre aspectos literários, estéticos, e não menos importante da obra gráfica do pintor. Isto de certa forma ganha complementaridade e profundidade, também acertando alguns problemas que encontrávamos na obra de Sandoz, no catálogo organizado por Louis-Antoine Prat: Dessins de Théodore Chassériau. Dois volumes publicados em 1988.

Também de profunda importância para a propagação e enriquecimento crítico à obra de Chassériau foi a exposição ocorrida em três tempos em 2002. Chassériau: Un autre romantisme. Primeiramente no Grand Palais, depois no museu de Strasbourg e finalmente no Metropolitan Museum of Art de Nova York. Esta exposição gerou diversos artigos e estudos sobre o pintor. O catálogo da exposição contém um rico acervo gráfico além de uma importante explanação sobre as obras que foram expostas. Por intermédio também desta exposição, uma outra monografia 
foi realizada: Théodore Chassérian de Christine Peltre editado pela Galimmard em 2001.

Os estudos se multiplicam e as teses parecem concordar desde o inicio já em Chevillard com a importância de Théodore Chassériau para a pintura, não apenas identificando um epígono de duas correntes possivelmente antagônicas do século XIX, mas o colocando com um artista que conseguiu mostrar-se como original. Ademais, mais do que isso, identificando em Chassériau uma possível abertura para compreender certa produção moderna, como aquela de Paul Gauguin.

Nascido em 1819 na ilha de São Domingos (atual República Dominicana), um pouco mais de dois anos após seu nascimento, é levado juntamente com toda a família à Brest e em seguida à Paris, onde estabeleceriam o novo lar. Muito provavelmente este deslocamento para Paris ocorreu devido a preocupações dos pais em oferecer uma boa educação a seus filhos. Entretanto, o pai que, trabalhava com longas viagens logo se ausenta; a mãe, pouco tempo depois vai ao encontro do marido. Assim, o irmão mais velho, Frédéric Chassériau, passa a ser o preceptor de seus outros irmãos, Théodore inclusive. Chassériau, que desde cedo executara diversos desenhos, tinha a idéia fixa de ser pintor e integrar o atelier de Ingres. É o que ele diz a seu irmão, Frédéric, quando este certo dia pergunta o porquê de uma grande melancolia. Era feriado, e logo o pequeno Chassériau deveria voltar às aulas e dividir o tempo entre a educação da qual estava destinado a receber e as aulas de desenho. Como nos relata Chevillard, em seu clássico estudo sobre o pintor:

"Ele queria ser pintor e receber lições de Ingres, de Ingres e de mais ninguém. Frédéric entendeu que se encontrava na presença não de um capricho de uma criança preguiçosa e teimosa, mas de uma exaltação irresistível, contra a qual ele não deveria lutar". (Chevillard, 2002: 11).

Chassériau estava então com 10 anos, e Ingres neste momento já contava com uma grande reputação. Ingres foi o mestre da linha. Em suas obras, a crítica exaltava a capacidade exímia do desenho, o traço forte e bem delineado. Segundo Coli, "Ingres possui verdades inabaláveis: o desenho é superior à cor; as marcas do pincel devem ser absolutamente banidas; a natureza deve ser corrigida; a arte não surge da febrilidade, mas da paciência" (Coli, 2006: 277). Assim, é um pintor considerado com linguagem clássica de Rafael, Poussin etc. Mas, como nos esclarece Henri Focillon, a pintura de Ingres também pode ser encarada como romântica, e 
apenas a partir de 1830 uma oposição declarada se levanta: "O nome de românticos é logo reservado aos coloristas, e aos 'pintores', os desenhistas são considerados como clássicos...".

Chassériau consegue, por meio de um amigo de seu irmão (o também pintor Amaury-Duval, que já era aluno de Ingres), entrar para o atelier do mestre. Não só é admitido, como em pouco tempo torna-se o aluno preferido de Ingres.

Em 1836, dois anos depois de ingressar no atelier de Ingres, Chassériau participa de seu primeiro salão oficial. Ele apresenta Caim Maldito, numa composição sóbria enfatizando o drama pelos personagens que se mostram cabisbaixos. Por certo, nesta composição, podemos ver um aluno de Ingres, o cuidado com o qual o corpo é tratado, suas formas, de certa maneira nos remetem a seu mestre. Porém, a crítica que já neste quadro identificava um romantismo que não podia ser encontrado no atelier de Ingres, me parece lícita. O estilo mais passional encontrado, sobretudo na figura à direita acena para este viés. Este quadro lhe rendeu uma medalha de terceira classe que segundo Sandoz era uma "distinção apreciada nesta época, que de chofre o coloca na falange de artistas que fundam a esperança na pintura”.

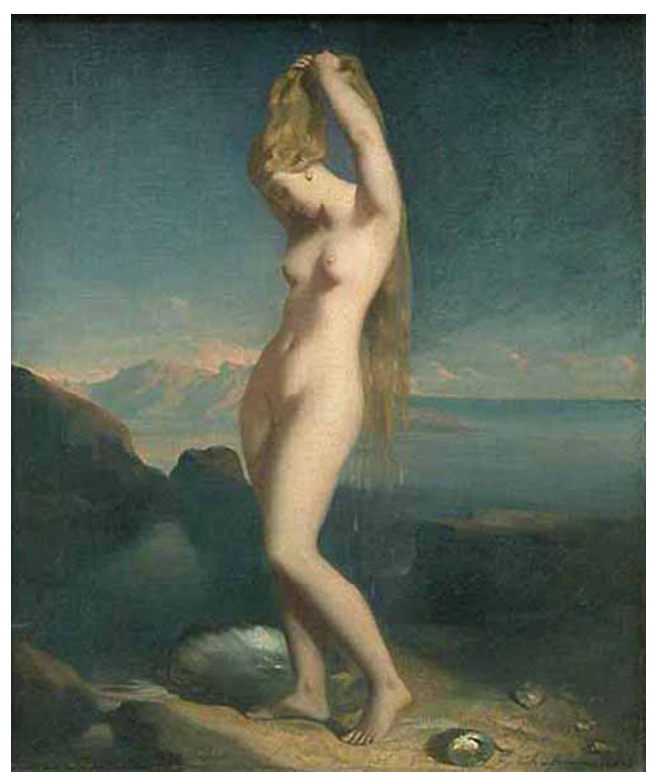

Vênus Anadiômene ou Vênus Marinha - 1838, museu do Louvre 
Muitos críticos concordam que apenas no salão de 1939 ele nos apresenta algo verdadeiramente novo. São apresentados os quadros Vênus Marinha ou Vênus Anadiômene e Suz̨ana no banho. No primeiro caso, vemos com justeza o comentário de Focillon, quando dizia que se tratava de uma "estatua de marfim posta à margem da água azul onde reside uma emoção indefinível, uma espécie de tristeza divina". A figura ingresca da Vênus entra em contraste, ou melhor, harmonia com elementos distantes daquele ambiente romântico até então. Sandoz aponta para uma aproximação com mestres pré-barrocos, dos quais Ticiano notadamente, e com o maneirismo florentino o que acabaria por apresentar uma nova faceta do romantismo. Entretanto, me parece, no que tange à apresentação pictórica, Chassériau se mantém fiel às doutrinas representativas de Ingres, mesmo que nos apresente seu mestre do início do séc. XIX, no qual era mais aproximado a tendências arcaicas, que pode ser visto com clareza nos primeiros trabalhos, como Vênus feriada por Diomedes de 1805. Como atesta Friedlaender:

"Quando, mais tarde, ele pinta Tétis vindo em socorro de Júpiter, o movimento e a forma do corpo, embora mais perfeitos e mais refinados, são os mesmos da Vênus de sua pintura anterior. Praticamente todas as mulheres, Francesca ou Angélica, têm algo daquele caráter arcaico e ao mesmo tempo de uma graça sensual" (Friedlaender, 2001: 110).

Certamente, o pintor também, para compor este quadro, teve bastante influência da literatura, sobretudo na poesia de Théophile Gautier, Victor Hugo e Alfred de Vigny. Mas o tom e importância que Marc Sandoz confere a este caráter parecem um pouco exagerado. Como se isto fosse uma fonte única da qual o pintor tenha se nutrido. Parece-nos mais lícito seguir os passos que apontam para a ampla iconografia deste tema, da qual Chassériau pôde ter contato, como a Vênus Anadiômene de Ticiano (que fez parte da coleção do Duque de Orléans) e mesmo, mais próximo dele, a obra homônima de seu professor, que passou quarenta anos, a partir de 1807 trabalhando neste quadro.

Chassériau parte para Roma com "uma espécie de curiosidade universal" (Sandoz, 1974:28), anota, faz séries de estudo em aquarela; estudos estes que seriam mostrados a Ingres. Neste momento seu antigo mestre já estava em Roma, pois havia aceitado a direção da Academia da França em Roma (Villa Médicis). O que fez com que Ingres fechasse seu atelier em dezembro de 1834; como neste período Théodore Chassériau era seu aluno predileto o qual o mestre depositava mais esperanças, todos os outros confiaram a Chassériau que, em nome do grupo, lhe desse um presente. 
Ingres encoraja seu jovem aluno a seguir para Roma como um amigo para continuar seus estudos.

Entretanto, Chassériau, não se manteve estancado aos preceitos ingrescos e, principalmente nestes 1840, começa a enveredar-se por caminhos diversos, senão até então antagônicos. A carta de Chassériau endereçada a seu irmão Frédéric em 9 de setembro de 1840, atesta de modo incrível o espírito do jovem pintor. A divergência latente entre mestre e aluno que antes fora exclusivamente uma relação de admiração mútua:

"Em uma longa conversa com Ingres, eu percebi que sob muitos aspectos nós nunca poderíamos nos entender. Ele viveu seus anos de força, e ele não possui nenhuma compreensão das idéias e das mudanças que são feitas nas artes de nossa época; ele está numa ignorância completa, de todos os poetas desses últimos tempos". (Chevillard, 2002: 26-27).

Uma ruptura que certamente teve fatores positivos na obra de Chassériau, que pôde então perseguir mais livremente seus anseios. Henri Lehmann (também aluno de Ingres) testemunha neste mesmo ano em uma carta dizendo que Ingres e Chassériau, "estes dois homens de gênio, representam respectivamente o passado e o futuro".

A partir de então, há uma aproximação ao romantismo de Delacroix, ou seja, dando uma importância maior às cores e ao subjetivismo. Friedlaender, sobre Delacroix, esclarece dizendo que "sua arte era totalmente dedicada à ênfase colorista e ao movimento e, portanto, do ponto de vista estilístico, deve ser considerada um estilo puramente do alto barroco, que se desvencilhou das persistentes exigências estáticas e ideais do neoclassicismo, assim como de qualquer propensão ao naturalismo". (Friedlaender, 2001: 163).

Focillon, entretanto nos fala da dicotomia entre linha e cor e do modo de como abordar essas duas tendências:

\footnotetext{
"Devemos alias tomar cuidado com esta distinção entre desenhistas e coloristas, em seu sentido literal, está pouco fundado. Delacroix é desenhista. Ingres é colorista. Mas um apreende a forma no movimento da paixão e na agitação da vida, enquanto o outro interpreta como expressão de uma ordem soberana e duma harmonia onde a potência mesmo do caráter concorre ao equilíbrio". (Focillon, 1927: 272)
}

Mas, o cenário crítico, e também assumido pelos pintores, é de rivalidade entre a linha (comandada então por Ingres) e a cor (representada por Delacroix). A aproximação, ou afinidade, entre Chassériau e Delacroix, torna-se mais clara a partir de 1944, nos desenhos em água-forte feitas a partir de Othello de Shakespeare. Os críticos não hesitam em afirmar a 
aproximação estilística entre dos dois pintores, mas muitas vezes, depreciando Théodore Chassériau, indicando que este havia feito cópias sem escrúpulos de Delacroix. Baudelaire, entre eles, foi um crítico que não conferiu muita importância à Chassériau; sobre tais gravuras do pintor, ele pondera que "todo mundo notou a preocupação em imitar Delacroix", como se este estivesse equivocado na utilização de alguns preceitos do mestre romântico ou não soubesse nem ao menos copiá-lo de maneira adequada.

Assim como Delacroix, Chassériau parte para uma viagem à África em 1846. É uma época de transição para o pintor, não apenas na forma de compor suas obras, cada vez menos ingrescas, mas também uma abordagem da qual o vemos menos arraigado a temas da grande literatura. Suas obras passam a tratar mais do cotidiano, dos "meios mundanos". Segundo Sandoz, também é uma época em que Chassériau começa a conferir mais importância aos esboços, geralmente pintados, abrindo vias para quadros que não seriam executados. O orientalismo já era um fato nas artes daquele século XIX, e muito se tem dito sobre a procura de novos meios para executar novas cores e formas. Infelizmente a tela que ele apresentou ao Salão de 1847 (O Sabbat dos judeus) foi destruída, entretanto sabemos por Vincent Pomarède que foi uma obra que "não convenceu seu público apesar do grande entusiasmo de Gautier". Embora ela tenha sido recusada em 1847, no ano seguinte ela é aceita.

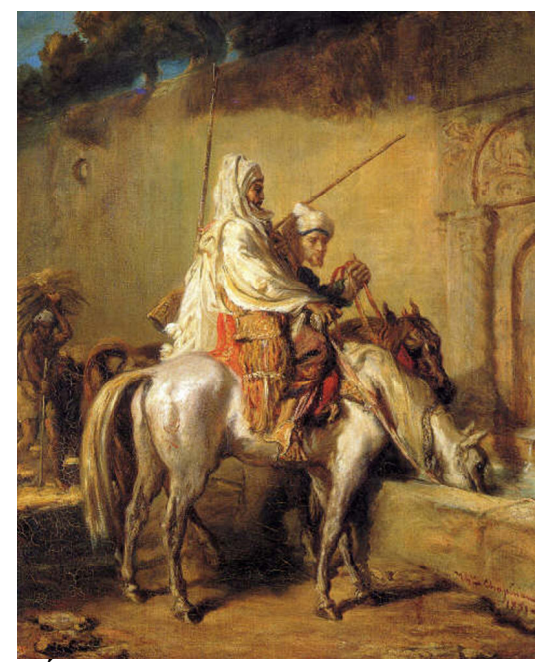

Árabes dando de beber aos cavalos, 1851 
Sua obra pode ser entendida neste entremeio, neoclassicismo e romantismo, mas seria ilícito estancá-lo como se fosse um pintor indeciso, e mesmo um pintor medíocre. O que gostaríamos de enfatizar em nossa comunicação é a tese de que ao alinhar, ou juntar, tendências consideradas antagônicas, sua obra singular emerge. Parece-nos também que há um ponto de encontro dos críticos quando se referem à decoração que ele fez para Cour de comptes entre 1844 e 1848. A obra maior de Chassériau que foi consumida quase inteiramente pelo incêndio da Comuna em 1871. Sandoz esclarece:

"Sabemos que esta obra considerável, e que teve profundos ressentimentos no século XIX, está hoje destruída. Podemos contudo ter um bom conhecimento pela descrição completa e detalhada fornecida por Théophile Gautier, pelas fotografias de Arthur Chassériau feitas imediatamente após o incêndio; por outro lado o Louvre conserva alguns quadros e fragmentos de quadros que permitem julgar o que foi a execução. A importância da obra e de suas repercussões merece um estudo mais detalhado" (Sandoz, 1974: 39).

Tratou-se de uma grande obra de decoração laica, composta de afrescos e quadros, que atestam de alguma forma um novo patamar alcançado pelo artista.

Ademais, como afirma Focillon, a partir desta união de forças contrárias é exigida das novas gerações outra coisa, um outro pensamento diverso daquele de apenas tomar partido entre duas tendências. Por este ponto de vista, a obra de Chassériau torna-se poderosamente fértil para as transformações nas artes que se seguiram, notadamente a partir do realismo de Courbet. 


\section{Bibliografia}

Baudelaire, Charles. Poesia e Prosa : volume único. 1ed. Rio de Janiero. Nova Aguilar, 1995.

Chevillard, Valbert. Un Peintre Romantique : Théodore Chassériau. La Rochelle. Rumeur des Ages, 2002.

Coli, Jorge. "Pinturas sem palavras ou Os paradoxos de Ingres". In: Novas, Adauto (org.). Artepensamento. 1ed. São Paulo. Companhia das Letras. 2006.

Focillon, Henri. La peinture au XIX siècle. 1ed. Paris. Renouard, 1927.

Foucart, Bruno. «Chassériau ou la beauté bizarre ». In : Connaissance des arts, n592, março de 2002. pp. 66-73.

Friedlaender, Walter. De David a Delacroix. Trad. Port. L. V. Machado.1ed. São Paulo. Cosac Naify, 2001.

Guégun, Stéphane et. Al. Chassériau. Un autre romantisme. Paris. Beaux Arts magazine, 2002.

Prat, Louis-Antoine et. Al. Chassériau. Un autre romantisme. 1ed. Paris. RMN, 2002.

Peltre, Christine. Théodore Chassériau. 1ed. Paris. Gallimard, 2002.

Sandoz, Marc. Théodore Chassériau: 1819-1856. Catalogue raisonné des peintures et estampes. 1ed. Paris. Arts et Métiers Graphiques, 1974. 